\title{
Decentralized Planning for Pre-Conflict and Post-Conflict Management in the Bawku Municipal Assembly of Ghana.
}

\author{
Thaddeus Arkum Aasoglenang \\ Department of Community Development \\ Faculty of Planning and Land Management \\ University for Development Studies \\ Wa. Ghana \\ Email:aasogthad@yahoo.com \\ and \\ Cuthbert Baataar \\ Department of African Studies and General Studies \\ Faculty of Integrated Development Studies \\ University for Development Studies \\ Wa. Ghana
}

DOI:http://dx.doi.org/10.4314/gjds.vgi2.4

\begin{abstract}
Decentralized governance in Ghana is aimed at spreading development. Such intention to some extent is marred by communal conflicts. A case studied for this paper is on the Bawku conflict. The Bawku Municipal Assembly, over the years, has put in measures to prevent further conflict but has failed to bring an end to the long waging conflict that continues to explode from time to time. This paper examines the role of the Municipal Assembly in the Bawku conflict, as the planning authority, for the ways that it uses that function to plan toward overcoming the conflict. Framed as a case study, purposive and random sampling techniques were used to select institutions and respondents for interviews. The study revealed that the Assembly had not been able to implement its Development Plans. The dynamics of the conflict also indicates that the feuding factions have maintained their opposing positions. Besides, the Assembly has never prepared any conflict management plan in order to address the recurrent conflicts. The study concludes that a collaborative approach though difficult, is a better option for conflict management between feuding factions. There will also be the need for the Assembly to be interested in designing conflict management plans, strengthening the capacity of the Municipal
\end{abstract}


Planning and Coordinating Unit, the capitalization of a conflict planning programme and the adoption of decentralized institutional arrangements for conflict monitoring and evaluation. Such processes are 'sine qua non' to pre-conflict and post-conflict prevention.

KEY WORDS: Decentralization, Conflict, Pre-conflict, Post-conflict, Planning, Management

\section{Introduction}

It has been observed that after achieving political independence, many governments in sub-Saharan Africa were faced with numerous development challenges. Hence, the government have focused their attention was on nation building. They invested heavily in programmes that have been centrally-managed around the 1950 os and 1960s To address the shortcomings of the centrally-managed programmes in the 1970 and early 1980 s, some of the countries especially Ghana, opted for public sector reforms resulting in the introduction of decentralized governance in order to facilitate development at the grassroots level. This has been intended to serve as a vehicle to 'distribute the benefits of economic growth more equitably to increase the productivity and income of all segments of society and to raise the living standards of the poor...' (Akuoko-Frimpong, 1994: 1). However, the very good reform effort to some extent has not yielded much result in some districts and regions in Ghana due to the emergence of conflicts and hostilities.

The Bawku Municipality has experienced numerous inter-ethnic conflicts since the 1930 due to chieftaincy succession disputes. The consequences of such conflicts on the people have been enormous. Referring to the subject matter, Harris (1999:15) in a study of "The Cost of Armed Conflicts in Developing Countries," indicated that violence had several economic implications including closed health posts, absence of teachers, empty shops and markets. It also means food shortages due to the disruption of farming, transportation and trade. Presently, the study area of this research is likened to the above description. This development has created a new dimension in the social life of the people where children (potential marriage partners) are discouraged from engaging in any affair $s$ with their colleague children from so-called "enemy" ethnic group. For over a decade now public sector workers have left the Municipality while others refuse posting to the area. This leaves the Municipality with reduced technical capacity for delivering its planned development agenda. Also, farming activities have been disrupted as a result of the reluctance of land owners to give lands to farmers of ethnic minority groups leading to the loss of their contribution to agricultural productivity in the area.

The Bawku Municipality, which was created by the Legislative Instrument (LI) 1439 in 1989 and charged with the responsibility of ensuring the overall development of the place, has not been able to find any lasting solution to the problem of violent conflicts. Article 240 (2) (b) of the 1992 Constitution of the Fourth Republic of Ghana stipulates, among others, that measures should be taken to enhance the capacities of local authorities to plan, initiate, coordinate, manage and execute policies in respect of matters affecting the 
local people. The Local Government Act, 1993, Act 462 also emphasizes the important role that District Assemblies (DAs) can play in the New Planning System. More importantly, Section 46 (1) and (2) of the Act, which establishes them as District Planning Authorities with these planning functions provided in Section 2 of the National Development Planning (System) Act, 1994, Act 480. This therefore means that planning is an important component for the success of all development initiatives, which implicitly includes conflict management. Due to the enormous powers at the disposal of the DAs, it was the expectation that the Bawku Municipal Assembly would have been in a position to explore the dictates of the Acts in order to embark on specific and strategic planning on addressing the conflict situation but this is not been the case.

Indeed, several plans have been formulated over the years by the Municipal Assembly but the prevalence of conflicts has remains. Civil Society Organizations (CSOs) have for some time now, devoted considerable amounts of resources in support of the Bawku Peace Initiative (BPI), which has aimed at bringing lasting peace and order to the area but the conflict still looms in the area. This state of affairs leaves much to be desired. Thus divergent actors have capitalized on the inherent weaknesses to perpetuate conflict in order to enforce their positions. In the midst of this, two main questions could also be asked thus: 1) Does the Municipal Assembly consider a conflict resolution and management mechanism as an important ingredient in programme/project success and therefore requiring mainstreaming? 2) In the wake of the prolonged conflict, how is conflict managed through the district development planning processes of the Bawku Municipal Authority? It is in this respect that the study seeks to examine how conflict is viewed as a development problem, thus requiring special attention to be addressed through district planning. It also looks at systems put in place within the context of development planning to optimize the achievement of development goals and especially poverty reduction in the Bawku Municipal area.

\section{Methods}

A case study method was used in the study. This approach allowed the researcher to do an in-depth and concentrated investigation and analysis on the measures put in place by the Bawku Municipal Assembly and other institutions for prompting, preventing and managing conflicts. Data collection and presentation were largely qualitative. Participants for the study were identified using purposive sampling techniques resulting in the selection of 5 Zonal Councils out of 12, settlement sections and 19 functional departments/organizations for interview. In addition, random sampling technique was used to select 60 respondents each from the feuding factions comprising the Kusasi and Mamprusi by settlement for interview. Intensive desk study was done to review literature in the form of reports, textbooks and journal articles. Six zonal/area councils in addition to the only urban council were randomly selected for the study. They included the Bawku Urban Council, Mognori Zonal Council, Zawsi Zonal Council, Kuka-Zabugu Zonal Council and Binduri Area Council. 


\section{Conceptualizing Planning as a Tool for Conflict Management}

\section{Conflict}

Conflict has been a difficult concept to define and authors on the subject have not been able to come out with a common but rather related definition. However, conflict generally can be defined as a natural disagreement resulting from individuals or groups that differ in attitudes, beliefs, values or needs. It can also originate from past rivalries and personality differences. It is also seen as a social phenomenon that can result from instantaneous or gradual changes that create diverging interests and needs. This means that conflicts are inevitable in the human environment. They occur under situations where actors have 'incompatible goals'. Indeed, it is the purposeful behavior of protagonists of capturing more of scarce resources, and/or overcome the strategies of other protagonists (Chris, 2004: 4) or even fight for their due which results in conflict. Also, Ninsin (1995) in his work summarized conflict as a struggle for access to opportunities, life chances-to the existing rights and privileges of society - which define citizenship within the nation-state. Citizenship here refers to the rights and obligations associated with membership of the nation-state. Furthermore, conflict is the means by which deprived groups seek to attain those rights and privileges which define one's opinion in the prevailing political order. Therefore, denial of these; what Darhrendorf (1990:50) calls "entitlements," is a denial of citizenship and an invitation to conflict. For the purpose of this work it can be stated that conflict occurs when competing group goals, objectives, needs or values clash and hang unresolved, leading to the build-up of frustration and aggression.

\section{Conflict Management at the District Level}

"Management" in this context means the generation and implementation of tangible improvements in a conflict situation. Therefore, conflict management can be thought of as "making progress" toward containment and eventual resolution. As part of improving the situation, progress can include ideas for developing mutual gains, learning to resolve disputes, achieving agreement, and laying a foundation for future negotiations (Ramirez, 2002). This process can be facilitated through legitimate and democratic institutions. This definition could be extended to cover all the efforts that go into handling conflict with its intricacies as experienced in the Bawku area. Though these definitions are relevant to the work they will be more effective in the management process if stages of conflict are defined using "levels of violence" as demonstrated by Samarasinghe (1999) in figure 1 which classifies the stages into five levels and by five phases. 
Figure 1: Levels and Phases of Conflict Model

\section{Phases of Conflict Model}

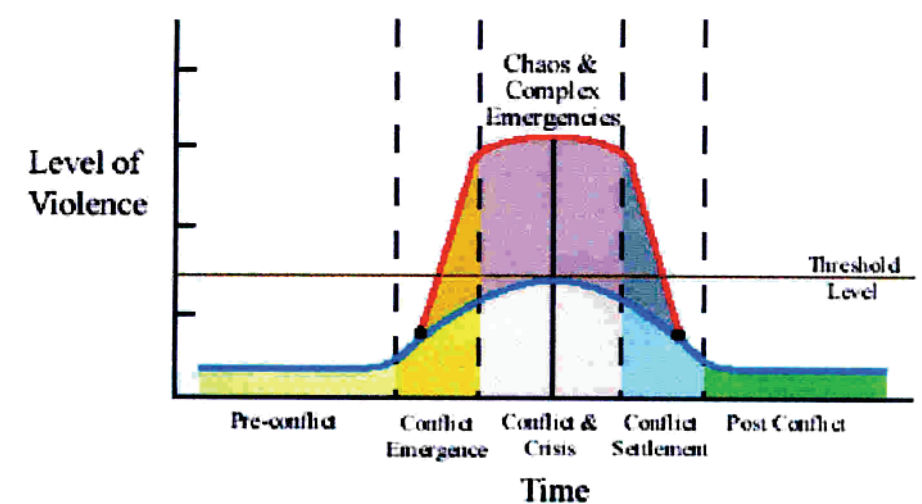

Source: Samarasinghe (1999).

For the purpose of the study, the phases of conflict are re-classified into three instead. These include Pre-conflict, Conflict and Post conflict phases as a requirement for strategic planning and management of conflict through district development planning. These phases are interconnected in order to re-enforce one another (Figure 2). The study in this regard considers pre-conflict and post-conflict phases as critical planning stage if we are to avert violent conflicts.

In order for the District Assembly to manage conflict situations sustainably, there should be the need to devise the most effective operational procedures based on the nature of the conflict. Besides, for the operational mechanism so designed to be effective, it will have to be "institutionalized in such a way as to commit politicians and governments to certain responses that become part of the routine" (SAIS 2004). Figure 2 is a threephase conflict planning model that should be institutionalized and this phase functions through planning in order to respond to looming conflicts before they become violent or otherwise. The process however ignores the second phase (violent conflict) because it is assumed that effective operational planning procedures should be capable of detecting Early Warning indicators (as in phase one) for prevention in order to avoid violent conflict. However, if conflicts occur, the crucial issue will be to handle them in ways that do not result in their repeat. In this regard, the post-conflict management process would have to be evaluated by the Planning Unit of the Assembly with support from other decentralized departments on the ground and action-oriented recommendations made for re-planning to re-enforce the containment of pre-conflict, especially early warning systems. 
Figure 2.Three Dimensional Planning Model for Conflict Management

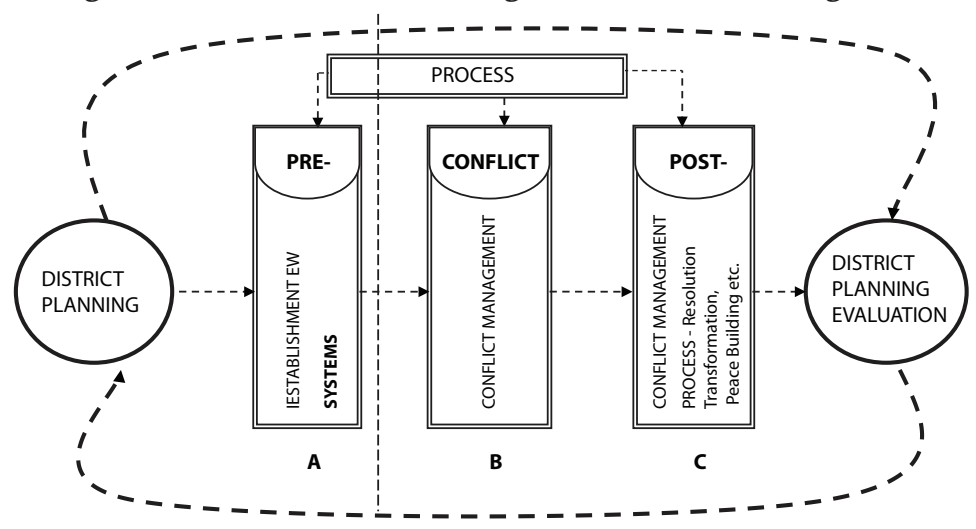

Source: Adapted/modified from Aasoglenang (2011. P. 43)

\section{A Basic Approach to Pre-Conflict Management Planning}

The nature of violence in conflict situations can take many forms. However, destruction may not take place until conflict reaches a mature stage (conflict and crisis). As argued by Ayee (1995: 240) "Conflict Prevention Mechanisms must be established at the institutional level to deal with grievances before they develop into hydra-headed conflicts." Decentralizing governance in a multi-ethnic environment especially in districts associated with high levels of poverty and illiteracy can create a potential ground for conflict. Though Samarasinghe's (1999) model is relevant to this work, he has not developed any comprehensive system for overcoming the conflict in it various phases. This study therefore, focuses on developing a planning framework for generating an Early Warning (EW) System that can predict conflict and devise the most effective operating procedures for managing conflicts.

\section{Early Warning System Approach}

The purpose of an EW system is to identify and track indicators of emerging conflict(s). The system is more effective when a district is in the web of "crisis life cycle," where it has experienced all the phases of conflict. In order to gather information on EW signs to manage conflict before they become violent, Samarasinghe (1999) proposes that the system should incorporate an assessment of structural variables to help do risk analysis and also factor in an evaluation of perception variables that help us to understand why individuals and groups take action against the state and resort to violence. In the light of this, Anthony (1988:5) citing Habermas (1976) identified the economic, political and socio-cultural sub-systems of society as the point of origin of crisis, which in some circumstances lead to the de-legitimization of the state and political eruption. These sub- 
systems should therefore be the areas of monitoring and assessment of EW indicators and signs as shown Fig 3. Within the scope of planning, districts can achieve the above by developing appropriate mechanisms for information collection and analysis on issues of conflicts. The indicators of conflicts must be identified, then monitored and evaluated by an impartial and multi-disciplinary team for the purpose of taking appropriate measures to deal with all forms of conflicts identified.

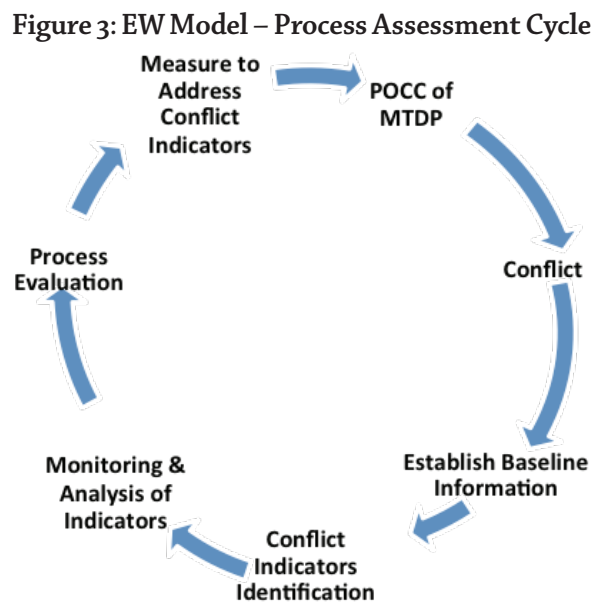

Source: Adopted from Aasoglenang (2011: 38)

It is apparent from the above that violent conflict will not occur if pre-conflict preventive planning is effectively in place because 'the earlier the reaction to an incipient conflict, the greater the opportunity of reversing a deteriorating situation. We can be forewarned of impending crisis through early warning indicators or signs' (SAIS, 2004). Early Warning therefore enhances basically three goals: prevention, mitigation and preparedness.

\section{Conflict Analysis}

It is important to note that the management procedures put in place in order to overcome conflict will not achieve the desire results without rigorous analyses. In view of this situation, it is crucial to examine and understand it from various standpoints. That is, the first step in conflict management is to analyze the conflict situation. This should "generally be done first in non-intrusive ways in order to avoid making the situation worse..." (Huggins, 2004:5). Therefore, this should be taken into consideration when doing desk analyses of conflicts. Generally this should focus on addressing three interrelated aspects: the nature of the conflict, its boundaries (geographical, temporal, and socio-cultural) and finally the actors directly or indirectly involved in the conflict. For this aspect to be achieved, it will require some fundamental conflict analysis tools for the planning process. Lewer and Freyer (2004:17-34) identified the tools to include conflict 
mapping, the onion, conflict tree, the $\mathrm{ABC}$-triangle, force field analysis, pillars and the pyramid. It is only through such multi-dimensional approach to conflict analysis that we can diagnose the dimensions of conflict in order to inform the Assembly about the choice of conflict management method/style to adopt.

\section{Post-Conflict Management Planning}

Post conflict management is vital to providing stable and sustainable environment for development to thrive. Therefore, "no price should be too high to pay in the quest for peace" and "no sacrifice should also be regarded to be too much to arrive at permanent and lasting peace" (Daily Graphic, 16.2.2005:13). In this regard, it is important to note that conflict, be it violent or non-violent requires stable institutions and stakeholders to transform it positively to an appreciable level, for it is believed to be "better for Government to negotiate with internal dissidents early rather than waiting until it gets worse" (Zartman, 1995:17). This creates the need for appropriate tools and approaches to manage conflicts. Against this backdrop, two basic approaches have been suggested. These are either the Integrative or Distributive approaches (Brilhart and Galanes, 1995:269). The Distributive Approach suggests that what one person gains is at the expense of another. The Integrative Approach is a win-win situation which also assumes that conflict can be managed in such a manner that all aggrieved parties end up being winners. While opting for the best approach; it should be so done within the context of planning because postconflict warning signals need to be contained to prevent subsequent escalation.

\section{Discussion of Results}

\section{Dynamics of the Conflict}

To assess the impact made so far by the Bawku Municipal Assembly and partners in the mediation process, aspects of the study was conducted solely among households of the main actors. There were the Kusasi and Mamprusi. This focused on their perception of the conflict situation in the Municipality. The data generated and presented in Table 1 below shows mixed feelings among the 60 respondents interviewed. For instance, $23.5 \%$ of the Kusasi and $30 \%$ of the Mamprusi were of the view that the conflict should continue. With regard to the effort made by the Assembly in the management of the conflict, $48.3 \%$ of the Mamprusi were of the opinion that the Assembly did not do well as against $36.7 \%$ of the Kusasi. The reasons were that the Assembly has also contributed to the conflict since some staff had not lived above reproach in terms of the equitable distribution of resources. The Assembly Members were deeply polarized on ethnic and party lines. Also, $61.7 \%$ of the Kusasi had suspicions that the Mamprusi could fight back at any moment and $70 \%$ of the Mamprusi had the same impression. It is obvious that the suspicion held by each of the ethnic groups against the other meant there was breach of trust. The Municipal Assembly, which is the Planning Authority, must therefore take precaution against any possible escalation 
Table 1: Dynamics of the Conflict

\begin{tabular}{|c|c|c|c|c|c|c|c|c|c|c|}
\hline \multirow{3}{*}{ ISSUE } & \multicolumn{10}{|c|}{ FREQUENCY OF RESPONSES } \\
\hline & \multicolumn{5}{|c|}{ KUSASI } & \multicolumn{5}{|c|}{ MAMPRUSI } \\
\hline & YES & $\%$ & NO & $\%$ & $\begin{array}{l}\text { Total } \\
\text { Responses }\end{array}$ & YES & $\%$ & NO & $\%$ & $\begin{array}{l}\text { Total } \\
\text { Responses }\end{array}$ \\
\hline $\begin{array}{l}\text { Necessity to } \\
\text { continue } \\
\text { With conflict }\end{array}$ & 14 & 23.3 & 46 & 76.7 & 60 & 18 & 30 & 42 & 70 & 60 \\
\hline $\begin{array}{l}\text { Conflict } \\
\text { managed well by } \\
\text { Assembly }\end{array}$ & 38 & 63.3 & 22 & 36.7 & 60 & 31 & 51.7 & 29 & 48.3 & 60 \\
\hline $\begin{array}{l}\text { Children } \\
\text { knowledge } \\
\text { About conflict }\end{array}$ & 43 & 71.7 & 17 & 28.3 & 60 & 41 & 68 & 19 & 32 & 60 \\
\hline $\begin{array}{l}\text { Suspicion of } \\
\text { each other }\end{array}$ & 37 & 61.7 & 23 & 38.3 & 60 & 42 & 70 & 18 & 30 & 60 \\
\hline $\begin{array}{l}\text { Conflict } \\
\text { externally } \\
\text { influenced }\end{array}$ & 27 & 45 & 33 & 55 & 60 & 36 & 60 & 24 & 40 & 60 \\
\hline $\begin{array}{l}\text { Agreed to terms } \\
\text { of BPI mediation } \\
\text { process }\end{array}$ & 44 & 73.3 & 16 & 26.7 & 60 & 26 & 43.3 & 34 & 56.7 & 60 \\
\hline
\end{tabular}

Source: Adapted from Aasoglenang (2011. P. 62)

\section{Mechanisms for Conflict Management}

For sustained peace to prevail in conflict districts there should be the need for the Assemblies to come out with plans that prevent pre-conflicts and manage the end-results of conflicts as illustrated in the conflict planning model (figure 3 ).

\section{Pre-Conflict Experience}

A study of past plans revealed that conflict was not a major issue to be concerned with by the Bawku Municipal Assembly. But for the 2002-2004 Medium Term Development Plan (MTDP) there was an acknowledgement of conflict in it as a major constraint to the implementation of development plans. However, the content of the plan had no deliberate designed strategies and programmes that explicitly focused on conflict as a development challenge requiring pragmatic management. Consequently, there was no single budget line created even though it was the case for all identified key development challenges in the MTDP to address the issues of conflict in the Bawku area. Two way implications can 
be derived from the findings: firstly that the conflict situation had been trivialized and secondly the planning functions of the Assembly had not been interpreted to include the powers or mandate to plan towards the prevention, resolution and management of the numerous and hydra-headed conflicts in the Municipality.

Currently, it is the Air Borne Force (ABF) station in Bawku, the Municipal Security Committee (MUSEC) and other security agencies that have taken over to prevent conflicts and maintain peace. But are they capable of undertaking pre-conflict management responsibilities as they relate to the development of the Municipality? Certainly not! Though the security forces have been managing the conflict through peace enforcement, there cannot be true conflict prevention and transformation without the active involvement and commitment of local actors. The Assembly and other third force conflict mediators in the Bawku area conflicts should in this wise take a cue that conflicts are caused by human actions and they will only be properly managed by the same human actions.

\section{Post-Conflict Experience}

Analyzed data also show that the management of post-conflict has the same outlook as the pre-conflict management process. For example, there are no institutional arrangements put in place to handle the end-results of the conflict in a sustained manner. However, further findings indicated that after the 2000/2001 deadly conflict, the Assembly supported the Bawku Peace Initiative to start a mediation forum between the Mamprusi and Kusasi. As part of the outcome of the mediation process, both the Mamprusi and Kusasi spelt out five point resolutions each to be observed and respected by all for peace to prevail in the Municipality. But for about a decade now the respective resolutions have not been observed (Text Box 1 contains the respective resolutions). It is evident from the analysis that farmlands confiscated from the Mamprusi have not been returned and intermarriages were still not encouraged. The Bawku Naba, though recognized and given all the courtesies he deserves by his kinsmen and visitors to the Municipality, the Mamprusi do not recognize or accord him the same respect. This state of affair indicates that the conflict management approach adopted in 2001 during the mediation forum and thereafter was more 'distributive' and did not address the fundamental issues(s) probably due to the complex nature of the disagreement. 
Text Box 1: Agreed Resolutions between the Mamprusi and Kusasi

\begin{tabular}{|c|c|}
\hline $\begin{array}{l}\text { Mamprusi } \\
\text { - Use the patronage of the Bawku market as a } \\
\text { unifying force for the people } \\
\text { - Use intermarriages between the Kusasi and } \\
\text { Mamprusi as unifying force } \\
\text { - Stop land confiscation especially among } \\
\text { - farmers } \\
\text { - } \quad \text { Allow all people especially council workers } \\
\text { to go back to their work places. }\end{array}$ & $\begin{array}{l}\text { Kusasi } \\
\text { - The Bawku Naba should be recognized } \\
\text { and given respect by all official guests to } \\
\text { the town } \\
\text { - The present political authority } \\
\text { (Assembly) be recognized and respected } \\
\text { by all } \\
\text { - All should do away with violence for peace } \\
\text { - All should respect and patronize each } \\
\text { other's socio-cultural practices. } \\
\text { - Groups should use dialogue as a means of } \\
\text { resolving all disputes }\end{array}$ \\
\hline
\end{tabular}

Source: Adapted from Aasoglenang (2011. P. 60)

\section{Conflict Management and its Implications on the MTDP of the Assembly}

The MTDP of the Assembly is the main development policy framework shaping the development path of the District. For any development policy to achieve such an objective, it must be operated in an environment devoid of violence. The study indicated that due to intermittent conflicts, successive MTDPs of the District over the years have not been successfully implemented. This implies that the development projects expected to spread and reduce poverty did not all materialize. The current conflict management strategy adopted by the Assembly relies entirely on the security agencies and occasional educational campaigns which offer no convincing hope for the future. It is therefore likely that future MTDPs will continue in the same way. They might not to see the light of insofar as there is continued failure to handle the conflict as a development challenge requiring rigorous planning rather than as a constraint outside the capacity of the Assembly.

\section{Identification and Management of Conflict Signals}

The findings show that currently there are conflict indicators in the Municipality that have one point in time generated into violent and non-violent conflicts. The study further revealed that some of the indicators especially those related to land were seriously looming and need to be properly managed before they turn violent. These signals include:

- Periods of party politics ;

- Display of party posters at will;

- Destruction of party posters; 
- Period for election/confirmation of Presiding Members and Municipal Chief Executives;

- Anonymous letter writing pointing at one faction or the other;

- Hype media reportage on the conflict;

- Wearing of provocative traditional dresses with 'talismans';

- Ownership and leadership of lorry park at Gingande;

- Land disputes especially at Zabugu;

To the extent that no conflict management plan was available to continuously track and address the identified signals, the study noted the lack of initiative in integrating conflict management into the planning process in the Municipality. There is the need for a functional conflict management framework capable of addressing issues of conflicts. The absence of such an arrangement in the Municipality means that the Assembly has not optimized the planning powers invested in it to deal with the situation. More importantly, the Sub-Districts that are an extension of the Assembly have not been empowered to monitor and report on possible conflict escalations. It is however likely that the Assembly cannot solve the problem alone but has the responsibility to define the way forward and then constitute an impartial and multi-disciplinary team to assist. Such a team should involve representatives of stakeholders of the conflict, selected institutions and organizations working in the field, faith-based organizations and, youth and women representatives, among others. It is expected that such a team will broaden the scope of monitoring events and getting vital information across for dealing with conflict-related problems in good time. Though the relevance of such a team cannot be underestimated, the individual's neutral and objective views of the entire process cannot however be guaranteed.

The management of deep-rooted conflict entails huge capital outlay. A suggestion for financial support for any operational conflict management plan received positive responses from development partners especially the Non-Governmental Organizations who are actively operating in and out of the Municipality. These organizations, especially those that started the Bawku Peace Initiative (BPI), have demonstrated their readiness to support any Municipal-wide conflict management plan that is capable of stopping conflicts. But this opportunity will come to naught if the Assembly does not treat conflict as a major development challenge requiring a project and move the process by developing proposals for raising funds for developing and implementing the plans. This step is necessary because public sector budget has not been enough to sustain the implementation of the plans. 


\section{Inputs for Designing Effective Conflict Management Plans}

An interview with 20 institutions and organizations including the Assembly revealed that there was the need to get all the stakeholders to the conflicts together to identify potential conflict indicators to be incorporated into the MTDP of the Assembly, which could be developed into a strategic plan to guide the management of the conflict in a more pragmatic way. The data revealed that their inclusion will generate important information needed for the exercise and also support the initiative. On the issue of committing resources for designing conflict management plans, the Assembly indicated its preparedness to fund such a project. Further interview with 6 out of the 11 Organizations that supported the Bawku Peace Initiative (BPI) in 2001 also suggested that they were prepared to provide funds and/or other resources to support the implementation of any conflict management plan for the area.

\section{Conflict Monitoring Team}

The study indicated that an effective team constituted to routinely monitor the issues of conflict in the field for timely responses was absent in the District. Some interest groups that could be part of the planned monitoring team were however identified by respondents to include; Civil Society Organizations involved in peace and justice-related projects, Faith-based organizations (FBO), Representatives of traditional leaders from all the ethnic groups, the Assembly including Municipal Security Committee (MUSEC), youth and women leaders. A team with such a composition will spread the representation and help build trust and confidence among stakeholders and as ell lead to the effective and objective evaluation of information gathered by the team. Such monitoring assignments could inform the authority early enough about the underlying conditions that promote conflict and inform the appropriate institution of any looming danger for decisive action to be taken to avoid any future confrontation or violence.

\section{Conclusions}

From the beginning, the study set out to assess whether the Municipal Assembly considered the recurrent conflicts in the District as a development problem that contributes to the spread of poverty and in that light whether planning as a tool is being used to manage the conflict. At the end of the study, it was revealed that conflict was duly acknowledged in the MTDPs of the Assembly but no institutional arrangement was put in place to develop relevant long-term plans to address it. Also, insofar as the Assembly has never planned to manage the conflict, no budget has ever been prepared purposely to support conflict management. Besides, though the conflict over the years has been mediated, its dynamics suggest that both the Kusasi and Mamprusi were still holding on to their entrenched positions. 
Based on the fact that the re-occurrence of the conflict was eminent, the responsibility rests on the Assembly to identify all early warning signals to be monitored against any possible escalation. The point of origin of the signals cut across the economic, political and socio-cultural sub-system of the people. In this case, a plan that involved objectivelyminded persons to monitor and gather information on the ground would be crucial for managing the conflict in a sustained manner.

\section{Recommendations for Strategic Institutional Action}

Within the context of the National Development Policy directives, Metropolitan, Municipal and District Assemblies with powers conferred on them are responsible for the promotion of development. However, development in its true sense cannot be achieved in a conflict environment and hence the responsibility lies with the DAs in Ghana to manage all conflicts when they erupt. Issues emerging from the study however show that the Bawku Municipal Assembly conflict management processes were based on ad hoc measures and not guided by any institutionalized plan. The needed Strategic Institutional Actions to be adopted in this regard should aim at guiding the Municipal Assembly and other development organizations interested in managing the conflict in the Municipality and elsewhere to integrate conflict management processes in their MTDP framework. These include the following;

\section{Conflict Management Plan}

It is important for the Assembly to seriously mainstream conflict in the MTDP of the Assembly by detailing the processes and indicators that should go into it. It should also be guided by an activity plan and a monitoring and evaluation framework. More importantly, a budget line should be created for it to support annual action plans. Besides, the Bawku conflict has passed through all the stages of conflicts and in this respect it will be appropriate to tailor the plan to cater for both pre-conflict and post-conflict phases as depicted in Figure 3. The Post-conflict Phase in particular is the most fragile phase/ period where the risk of resumption of conflict is high. There is therefore the need to continuously plan to cater for risk monitoring and assessment.

\section{Strengthening MPCU Capacity}

For any pragmatic conflict management plan to be developed it will certainly be the responsibility of the MPCU to facilitate the process. Insofar as the Unit is not familiar with what it takes to come out with conflict prevention, resolution and management plan(s) and their implementation, it is necessary to strengthen its capacity in critical aspects of conflict planning. This attempt will enable the MPCU to stay focused and positioned better for identifying all necessary indicators that should go into the preparation and implementation of conflict plans. 


\section{Decentralized Institutional Arrangement for Conflict Management}

The fact that the conflict affects everybody in all parts of the Municipality, it gives room to believe that its re-generation could start from any corner of the Municipality. Following from this, it is relevant to position the Municipal Assembly and the sub-structures in a manner that will enable them play more active roles in conflict management. This arrangement will involve developing appropriate mechanisms for information collection and analysis on issues of early warning signals at the grassroots. This will have to be done through a local network of relevant stakeholders who are familiar with the area and context of the conflict to carry out the day-to-day monitoring of change variables.

\section{Conflict Monitoring and Evaluation Team}

There is the need to form functional, impartial and multi-disciplinary monitoring teams to routinely track conflict related issues along the lines of the decentralized structures.

\section{Capitalization of Conflict Management Programmes:}

The preparation and implementation of conflict management programme(s) involve a huge capital outlay. The Assembly on its own will find it difficult to support such a programme. In this respect, it has to raise funds externally to complement internally mobilized ones in view of the fact that organizations and donors may be willing to support peace initiatives in the area. However, before such organizations could respond, the challenge will be on the MPCU to develop convincing fund raising proposals to get them committed to support any conflict management activities.

\section{Need for Synergy Building in Conflict Prevention and Management}

There is the need for effective synergy building between the government and traditional political authorities to find holistic and sustained solution to the impasse

\section{References}

Aasoglenang, T. A. (2011). The Relevance of Planning in Conflict Management in Ghana. LAP Lambert Academic Publishing GmbH. Dugweiler, 99,66123 Saarbrucken

Akuoko-Frimpong, H. (1994). “The Government's Decentralization Policy”. In: Tetteh, A (eds), Decentralized Development Planning in Ghana. Dept. of Planning, UST. SRS 10. Kumasi.

Ayee, Joseph R. A. (1995). "Conflict Resolution and Grievances Redressing Mechanisms at The District Levels in Ghana: Myth or Reality”. In Mike Oquaye (ed.) Democracy and Conflict Resolution. Gold-Type Publications. Accra.

Anthony, H. R. (1988). Immigration and Ethnic Conflict. Macmillan Press. Hong Kong. 
Bawku East District Assembly(2000). Medium Term Development Plan (2001-2004). Bawku, Ghana.

Brilhart, J. K. and G. J. Galane (1995). Be a Better Group Leader: Effective Group Discussion ( $\left.18^{\text {th }} \mathrm{ed}\right)$.

Brown and Benchmark Publishers, Dubuque.

Daily Graphic - 16/2/2005. P.13

Dougharty, J. and Pfaltzgraff, R. (1990). Contending Theories of International Relations: A Comprehensive Survey. Harper Collins Publishers. $3^{\text {rd }}$ ed. New York.

Ghana (2004). "Guideline for Operationalisation of District and Regional Planning Coordinating Units". NDPC and MLGRD.

Ghana (1992). Fourth Republican Constitution. Assembly Press, Ghana Publishing Corporation

Ghana (1988). L.I 1459.

Ghana (1993). The Local Government Act, 1993, Act 462.

Harris, T. Geoff (1999). “The Cost of Armed Conflicts in Developing Countries”. In Harris, T. Geoff (ed.): Recovery From Armed Conflicts in Developing Countries: An Economic and Political Analysis.

Lewer, N. and Fryer, M. (2004).“International Crisis Management Course.” Centre for Conflict Resolution. University of Bradford Reading Materials.

Ministry of Local Government and Rural Development (1996). The New Local Government System. $2^{\text {nd }}$ ed., Accra, Ghana: MLGRD (November)

Ninsin, Kwame (1995). “Conflict as Pursuit of Liberty”. In Mike Oquaye (ed). Democracy and Conflict Resolution in Ghana". Accra, Ghana: Gold-Type Publication.

Samaransinghe, Stanley (1999). "Conflict Management through the Crisis Life Cycle." Proceedings of the International Consensus Forum on Health and Human Security in Conflict and Transition Settings: Improving Policies, Strategies and Programs in Africa. Harare, Zimbabwe. (April 15-17).

Ramirez, Ricardo (2002).“A Conceptual Map of Land Conflict Management: Organizing the Parts of Two Puzzles”. FAO Rural Development Division. United Nations, Rome.

SAIS (2004). “Conflict Prevention: Early Warning Indicators and Signs”. Paul H. Hitze, School of Advanced International Studies. The John Hopkins University.1619. Massachusetts Avenue NW, Washington. 
Republic of Ghana (2004). The Local Government (Bawku Municipal Assembly) (Establishment) Instrument. Accra, Ghana: Assembly Press.

Zartman, I.W (1995). Elusive Peace: Negotiating an End to Civil Wars. The Bookings Institution. Washington, D.C. 